\title{
A meteorological feature in Shonan campus of Tokai University
}

\section{東海大学湘南キャンパスにおけるひとつの気象学的特幑}

\author{
Shin SOUTOME, Yuka ETO , Hiroki RYUO and Kazuo MIMURA \\ Department of Resources and Environment Science, school of humanity and culture, Tokai University \\ Hiratuka city. 259-12, Japan \\ Phone.81+463-58-1211 ext (3419) Fax.81+463-50-2208
}

( Received 15, November 1999 Accepted 13, March 2000 )

Although we experienced much snow in January 1998 at Kanto area, we had not seen remarkable snow accumulation in Shonan campus of the Tokai University and its environs. . In order to clarify the reason, observed wind data at 10th building of the campus were compared with the AMEDAS data at surrounding sites in 1998. It is found that monthly mean land-sea breeze component can be seen commonly in monthly mean daily change of southerly wind of Kanagawa prefecture. As an interesting feature of meteorological properties of the Shonan campus of Tokai University, it may be pointed out that the sea breeze component is dominant even in the winter season.

Keywords : Meteorology, Sea breeze, Snow accumulation, Daily change

\section{INTRODUCTION}

1998 年 1 月 8 日と 15 日に関東地方に記録的な大雪 が降った。神奈川県各地も例外ではなかったが、東海大学周 辺には、雪が積もらなかった。(Fig.1) またこの地域は昔か ら雪が少ない事で知られている。雪が降った日の前後 3 日間 の気温と風の変動を見たところ、東海大では降雪時間内に急 激な気温の上昇と風向きの変化が見られた。（Fig.2・Fig.3） 東海大付近に積雪がない理由を探る第 1 歩として、東海大学 湘南キャンパスにおける 1998 年を通した気象学的な特徽 を見つけ出す事を目的とし、10号館屋上で観測したデータ

（気象業務法の規格・法令を準用した、横河ウェザック株式 会社製の自動気象観測装置を使用した）之（財)気象業務支 援センターから得た気象庁のアメダスデータを解析した。

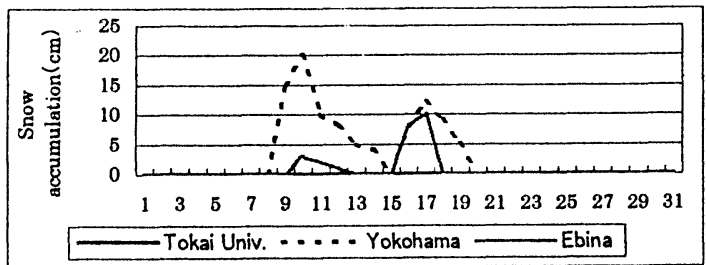

FIG.1.Snow accumulation in January 1998.

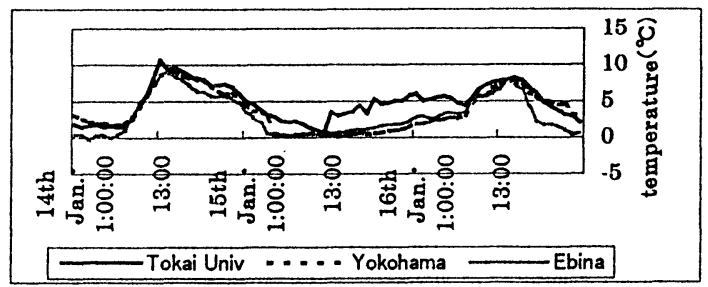

FIG.2. Atmospheric temperature on 14 16 th Jan. 1998.

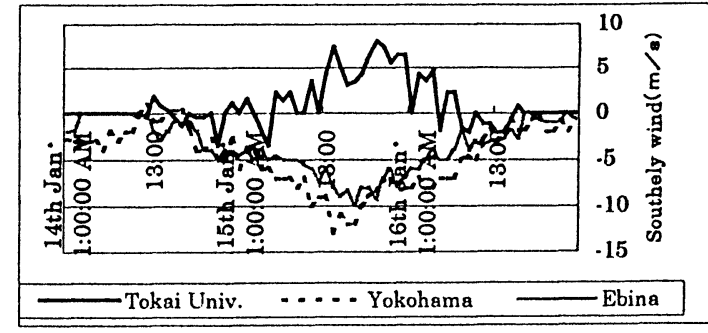

FIG.3.Temporal variation of southerly wind between 14 16 th .lan. 1998.

\section{DATAANALYSIS}

風に注目して解析を行った。

A. Annual mean and annual change of daily mean 1 年間の平均南風成分を各地で比較すると、東海大はほぼ 0であり、各地の中間である。

日平均した南風の変動を 1 年分並バると、数日スケール の変動が卓越しており、東海大・横浜・海老名・三浦・小田 原・辻堂の各地点 (今後は各地点と呼亏゙) 間の相関係数は 0.8 以上であった。この事は、各地で共通して、風の年間変 動が総観規模擾乱に支配されていることを示唆している。

B. Daily changes of annual mean and monthly mean 各正時の南北風を 1 年間にわたって平均し、その 1 日内の 変化を見ると、振幅の大きい横浜・海老名・辻堂グループ、 振幅の小さい東海大・小田原・三浦グループに大別されるが、 夜間の北風・昼間の南風という共通する特徵が見られる (Fig.4)。また、一般に正の相関が強く、小田原を除けば、 全ての地域間で相関係数が 0.9 以上になった。

続いて各正時の東西風、南北風を 1 ケ月に渡り平均し月 毎の日変化を求めた。 
各地点において年平均日変化と月平均日変化の相関を調 ベると南風成分については、東海大の 10 月・12月を除く と 0.7 以上であり、またほとんどの月で 0.9 以上であった。 すなわち年平均で表わした日変化パターンは季節的な普遍性 を持っている。各月毎の地点対地点の相関係数を求めてみる と、一般に正の相関が見られたが、特に横浜、海老名、辻堂 は全ての月で南風成分が 0.8 以上の高い相関であった。すな わちこの月平均南北風の日変化パターンはほとんどの月で空 間的にもまた普遍性をもっていることが判った。

各地点、各月の月平均日変化を比較すると、例えば Fig.5 のように夏期は東海大と横浜（神奈川県の他の地点も横浜に 似ている）の日変化は良く似ているが、Fig.6 のように冬期 においては横浜では 1 日中北風であるのに対し、東海大で は宣間に南風が見られた。この日変化を日平均值と変動部分 に分けたとき、後者を昼の海風・夜の陸風レ゚ターンに一致す るため「海陸風成分」と呼ぶことにする。

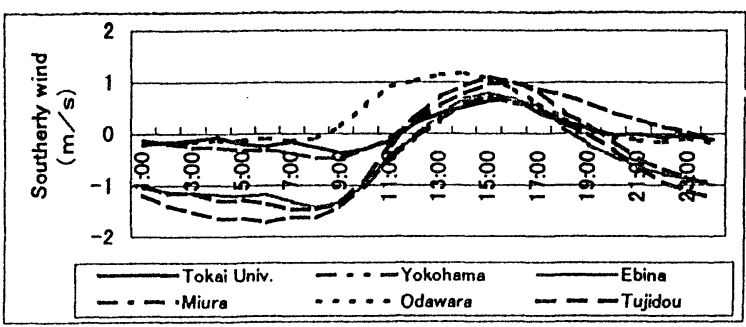

FIG.4.Daily change of annual mean southerly wind in 1998.
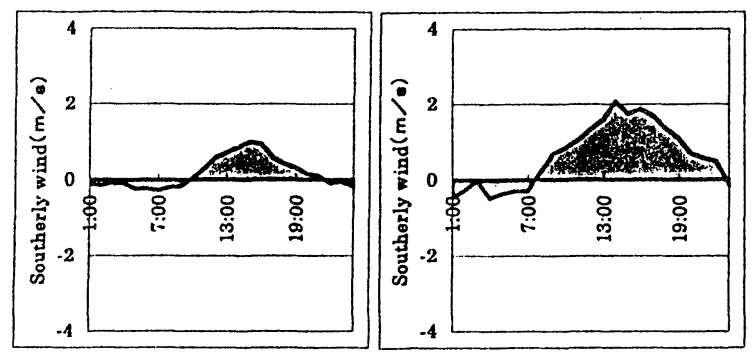

FIG.5.Daily change of monthly mean southerly wind at Tokai Univ. (left) and Yokohama (right) in July 1998.
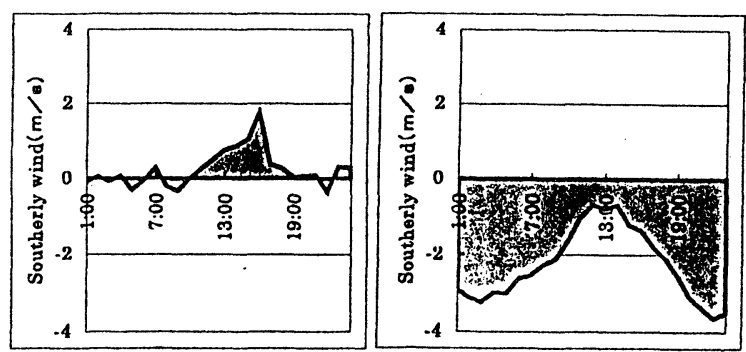

FIG.6.Daily change of monthly mean southerly wind at Tokai Univ. (left) and Yokohama (right) in January 1998.

\section{RESULTS AND DISCUSSION}

各月毎の平均南風と海陸風成分の目安として標準偏差を求 め、各地点で比較した。1，2月においては東海大以外はす ペて平均風が北風であるのに対し、東海大のみが南風であっ た。すなわち、横浜・海老名・辻堂においては海陸風成分が 強いけれども平均北風がそれを上回っているために 1 日中 北風が吹いている。それに対して東海大においては $1 ， 2$ 月 においても海陸風成分が平均風を上回り昼間の南風が見られ る。つまり、南風に注目すると東海大は冬らしくないとも 言える。(Fig.7·Fig.8)

この原因については現在のところ不明であるが、東海大付 近は山と海に挟まれているので、この地形的要因が関倸して いるのではないかと考えられる。

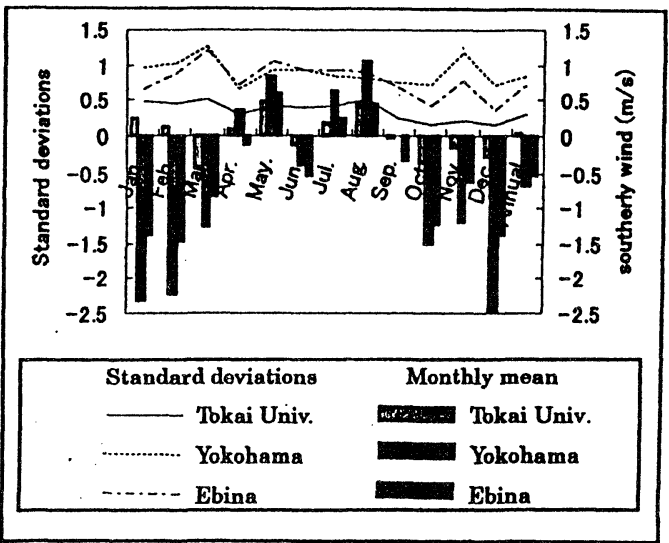

FIG.7. Seasonal progress of daily change of southerly wind in 1998 (Tokai Univ., Yokohama and Ebina).

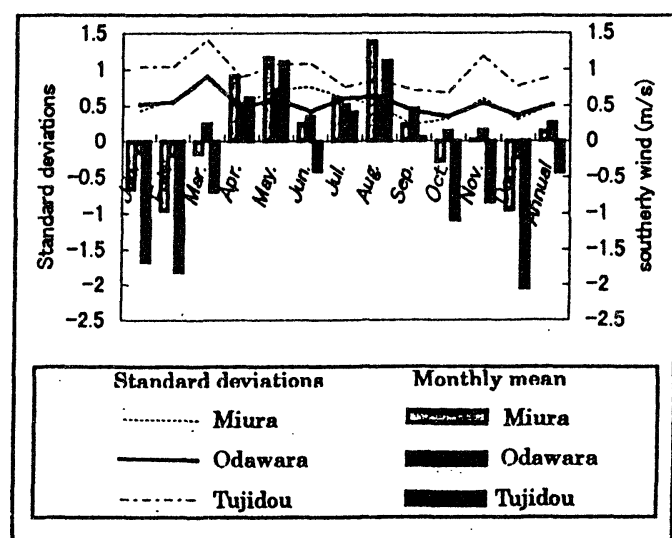

FIG.8. Seasonal progress of daily change of southerly wind in 1998 (Miura, Odawara and Tujidou).

Presented at '99 SAS Intelligent Symposium 